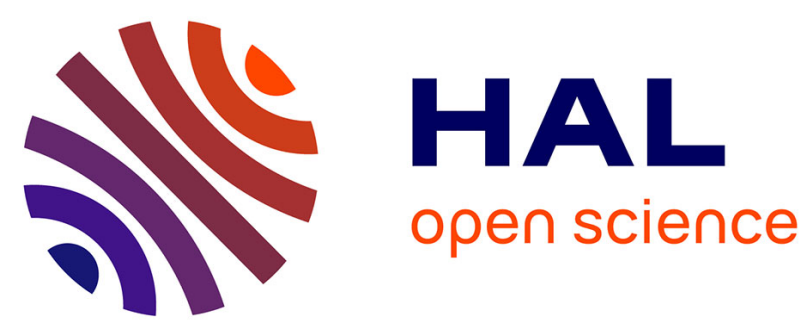

\title{
SEASONAL SURVIVAL OF GREATER SNOW GEESE AND EFFECT OF HUNTING UNDER DEPENDENCE IN SIGHTING PROBABILITY
}

Gilles Gauthier, Roger Pradel, Stéphane Menu, Jean-Dominique Lebreton

\section{- To cite this version:}

Gilles Gauthier, Roger Pradel, Stéphane Menu, Jean-Dominique Lebreton. SEASONAL SURVIVAL OF GREATER SNOW GEESE AND EFFECT OF HUNTING UNDER DEPENDENCE IN SIGHTING PROBABILITY. Ecology, 2001, 82 (11), pp.3105 - 3119. 10.1890/00129658(2001)082[3105:SSOGSG]2.0.CO;2 hal-02126397

\section{HAL Id: hal-02126397 \\ https://hal.science/hal-02126397}

Submitted on 11 May 2019

HAL is a multi-disciplinary open access archive for the deposit and dissemination of scientific research documents, whether they are published or not. The documents may come from teaching and research institutions in France or abroad, or from public or private research centers.
L'archive ouverte pluridisciplinaire HAL, est destinée au dépôt et à la diffusion de documents scientifiques de niveau recherche, publiés ou non, émanant des établissements d'enseignement et de recherche français ou étrangers, des laboratoires publics ou privés. 


\title{
SEASONAL SURVIVAL OF GREATER SNOW GEESE AND EFFECT OF HUNTING UNDER DEPENDENCE IN SIGHTING PROBABILITY
}

\author{
Gilles Gauthier, ${ }^{1,3}$ Roger Pradel, ${ }^{2}$ Stéphane Menu, ${ }^{1}$ And Jean-DominiQue Lebreton ${ }^{2}$ \\ ${ }^{1}$ Département de Biologie and Centre d'Études Nordiques, Université Laval, Ste. Foy, Quebec, Canada G1K $7 P 4$ \\ ${ }^{2}$ Centre d'Écologie Fonctionnelle et Évolutive, CNRS, 1919 Route de Mende, 34293 Montpellier, Cedex 5, France
}

\begin{abstract}
Although much of life-history theory assumes increased mortality at certain stages (e.g., migration), survival rates are rarely estimated on a seasonal basis within the annual cycle of migratory species. We estimated variations in seasonal survival rates in a long-lived, hunted species in the presence of short-term (between consecutive seasons) and long-term (between years in the same season) dependence in sighting probabilities. We also tested the two contrasting hypotheses that hunting mortality is either compensatory or additive to natural mortality. This study was conducted on adult female Greater Snow Geese (Chen caerulescens atlantica) from 1990 to 1998, and is based on 3890 neck-banded birds and 13657 resightings on the northern breeding grounds in summer, and southern staging areas in spring and autumn. Birds were 10-20\% more likely to be seen in autumn and spring if they were seen on the previous occasion (summer and autumn, respectively). Birds were $30-40 \%$ more likely to be seen in autumn and spring if they were last seen in the same season in the previous year. Differences in behavior according to family status (presence or absence of young) and heterogeneity in site fidelity may explain the dependence in sighting probabilities; failure to account for this may lead to biased survival estimates. Monthly survival rates from spring to summer (3-mo period) and summer to autumn (2.5mo period) were equal $(0.989 \pm 0.003$, mean $\pm 1 \mathrm{SE})$ and showed little variation over the years, even though the two lengthy migratory flights $(3000 \mathrm{~km}$ each) and breeding occurred during these periods. In contrast, monthly winter survival (from autumn to spring, $6.5 \mathrm{mo}$ ) was lower than during the other seasons and varied significantly over the years (range 0.936 \pm 0.021 to $0.993 \pm 0.008$ ). Mean survival of adult females (corrected for neck band loss) was 0.96 from spring to autumn, 0.86 during winter, and $0.83 \pm 0.05$ for the whole year. Natural mortality (i.e., excluding hunting) was equal among seasons and did not vary over the years, which suggests that mortality risk is not increased during migration or reproduction. There was a significant inverse relationship between winter survival and the kill rate $(b=-1.21 \pm 0.56)$, which suggests that hunting mortality was additive to natural mortality. This is probably a general feature of long-lived species because their low and relatively constant natural mortality rate does not allow them to compensate for an additional source of mortality such as hunting. Contrary to life-history theory, we did not find evidence that migration or reproduction entailed a survival cost in this long-distance migrant bird.

Key words: additive mortality; capture recapture; Chen caerulescens atlantica; Greater Snow Geese; hunting mortality; seasonal survival rate; sighting dependence.
\end{abstract}

\section{INTRODUCTION}

During the course of their annual cycle, animals may face variable mortality risks. Variations in mortality risks associated with activities such as reproduction or migration will shape the evolution of basic life-history traits. This is especially true in long-lived species in which population growth is much more sensitive to adult survival than to fecundity (Lebreton and Clobert 1991). Estimates of annual survival rate based on sound capture-recapture or band recovery methodologies are now available for some long-lived species (e.g., Croxall et al. 1990, Francis et al. 1992b, Cézilly et al. 1996, Prévot-Julliard et al. 1998). However, knowledge of

Manuscript received 24 April 2000; revised 16 September 2000; accepted 17 October 2000; final version received 27 November 2000

${ }^{3}$ E-mail: gilles.gauthier@bio.ulaval.ca how survival rate varies on a seasonal basis throughout the annual cycle of an animal remains poor (Blohm et al. 1987, Ward et al. 1997, Schmutz and Ely 1999). For instance, theories about the evolution of annual migratory behavior in birds assume that individuals experience a high mortality rate during migration (Greenberg 1980, Alerstam 1990). However, reliable estimates of survival rate during and outside migrations are rare (Nichols 1996).

In exploited populations, the effect of harvest on demographic parameters is a question of considerable fundamental and applied interest (Nichols 1991). It has long been recognized that hunting mortality can be compensatory to natural mortality, i.e., that most animals killed by hunters otherwise would have died of natural causes (e.g., predation, disease; Errington 1945, Boyce et al. 1999). Under some circumstances, however, hunting mortality may be additive to natural mor- 
tality, i.e., animals killed by hunters otherwise would have survived to reproduce again. The latter idea has been the dominant paradigm behind the management of waterfowl populations in North America for many years (Anderson and Burnham 1976, Nichols et al. 1984). Burnham and Anderson (1984), however, rejected the hypothesis that hunting mortality was totally additive in Mallards (Anas platyrhynchos), and found evidence that an increase in hunting mortality was compensated for by a decrease in natural mortality. Anderson and Burnham (1976) cautioned that the extent to which hunting mortality is compensated for by change in natural mortality may be reduced in species with a low natural mortality rate. In geese, which are relatively long-lived birds, some studies have found evidence that hunting mortality is additive (Francis et al. 1992b, Rexstad 1992, Hestbeck 1994). Tests of the additive or compensatory nature of hunting are commonly made on an annual basis, and, to our knowledge, have never been made on a seasonal basis, although such an approach should provide more insights into these processes (Nichols 1991).

When estimating survival rate, one has to rely on the recovery or recapture of marked animals. Two common problems encountered in recapture studies are heterogeneity of capture probabilities and trap dependence. Heterogeneity of capture occurs when some individuals consistently have a lower probability of recapture than others; the "transient effect," which occurs when newly marked cohorts include transient individuals, is one example (Carothers 1973, Pradel et al. 1995, 1997, Prévot-Julliard et al. 1998). Trap-dependence problems occur when some individuals temporarily avoid traps after being captured (trap shyness), or, on the contrary, become habituated to traps and return to them frequently (e.g., because of food inside the traps, trap happiness; Otis et al. 1978). Even when physical recaptures are replaced by resightings, dependence in sighting probabilities between successive occasions may occur, for instance because of differential habitat use (Sandland and Kirkwood 1981). Failure to account for capture heterogeneity or dependence in capture probabilities may lead to serious biases in survival estimates (Pradel 1993; R. Julliard, unpublished manuscript).

Our long-term population study of the Greater Snow Goose (Chen caerulescens atlantica), a long-lived and hunted species, provided an opportunity to estimate survival rate on a seasonal basis and to examine factors affecting it. Our sampling design offered several unique features. Briefly, adult females were captured and marked with neck bands once a year during breeding, and were resighted during two other discrete periods in their annual cycle: in spring at the beginning of the northward migration, and in autumn at the end of the southward migration. This enabled us to obtain separate survival estimates during three periods each year, including the winter season when most hunting took place. In spring and autumn, all birds from this population pass through the same staging areas along the St. Lawrence River, where extensive observations were conducted (Maisonneuve and Bédard 1993, A. Reed et al. 1998). Therefore, because birds that emigrated from the marking area could be resighted on the staging areas, our survival estimates were not biased low by permanent emigration, a common problem in capture-recapture studies. However, a preliminary analysis of this data set revealed significant dependence in sighting probabilities (Gauthier and Menu 1997), a problem also found in this analysis with more data. Several factors could contribute to sighting dependence in geese, including the family status (presence or absence of young) or fidelity to specific areas.

The objectives of our study were to (1) obtain unbiased estimates of survival rate in the presence of dependence in sighting probabilities, (2) examine variations in survival rate on a seasonal basis in a longdistance migratory bird, and (3) test the two contrasting hypotheses that hunting mortality is either compensatory or additive to natural mortality during the hunting season in a long-lived species.

\section{Methods}

\section{Field methods}

Greater Snow Geese were marked at the end of the summer on their arctic breeding ground every year from 1990 to 1998. Marking took place at the Bylot Island, Nunavut, Canada $\left(73^{\circ} \mathrm{N}, 80^{\circ} \mathrm{W}\right)$ colony, the most important breeding site for this population (for a description of the area, see Gauthier et al. 1996). Goose families were captured by mass banding drives during a 7-d period in early August when the adults were molting and before the young could fly. Birds were classified as adults ( $\geq 1 \mathrm{yr}$ old) or young based upon plumage, and their sex was determined by cloacal eversion. Banding occurred after nonbreeders (including yearlings), which molt earlier, had regained flight abilities. Therefore, virtually all adults captured were breeders and were at least two years old because Snow Geese do not breed as yearlings (Cooke et al. 1995). All birds received a U.S. Fish and Wildlife Service metal band, and most adult females received a plastic neck band with a four-digit unique code (for details, see Menu et al. 2000). Presence of neck bands was noted in all leg-banded females recaptured.

Observations of neck-banded geese were made in spring, summer, and autumn at several sites from 1990 to 1998. Therefore, "recaptures" were primarily resighting of neck-banded birds. Neck bands could be read at a distance of up to $500 \mathrm{~m}$ using $20-60 \times$ spotting scopes. During the summer, geese were resighted at their nest or during brood rearing on Bylot Island. Some physical recaptures occurred during banding in August, and these were added to the resighting data. At the end of the autumn migration, Greater Snow Geese have one 
major stopover along the St. Lawrence River in Québec from late September to early November (Maisonneuve and Bédard 1992, A. Reed et al. 1998). Intensive observations were made at all major staging sites throughout the autumn by $2-6$ observers every year. No observations were made on the wintering sites along the Atlantic coast (New Jersey, Delaware, Maryland, Virginia, and North Carolina), which were used from late October to late March. In spring, geese also stage for an extensive period along the St. Lawrence River (April and May), and intensive observations were again made during this period.

Resightings of geese could be divided into three distinct seasons: during the summer in the Arctic (15 June-20 August; $65 \mathrm{~d}$ ), and during the autumn (30 September-10 November; $40 \mathrm{~d}$ ) and spring (1 April20 May; 50 d) in southern Québec. The approximate midpoints of observations in each season were $5 \mathrm{Au}-$ gust, 15 October, and 1 May. The interval length between each season was therefore 2.5 mo from summer to autumn (5 August-15 October), 6.5 mo from autumn to spring (15 October-1 May), and 3 mo from spring to summer (1 May-5 August). In this study, the year started with the banding period and therefore extended from summer to summer. The length of the observation periods was relatively long compared to the interval length between periods, thus violating one assumption of the usual capture-recapture models (Lebreton et al. 1992). However, Hargrove and Borland (1994) showed that using extended observation periods induces a very small bias on survival if both mortality and capture probabilities do not exceed $50 \%$, which was the case here (see Results: Seasonal variations in survival rate and Sighting dependence effects).

\section{Estimation of kill rate}

Geese are hunted in southern Québec throughout the autumn (from early October until their departure in November), and in the United States from late October to late January. Subsistence harvest by native people occurs in summer and early autumn in the Arctic, but the number of birds killed is probably very small (A. Reed et al. 1998). We estimated sport harvest independently of the banding data, using the national harvest surveys designed for all migratory waterfowl species in both Canada and the United States (Boyd and Finney 1978). Age ratios (juveniles : adults) in the harvest are also estimated each year from tail fans sent in by recreational hunters participating in these surveys. The estimated total harvest of adult Greater Snow Geese (both sexes) was extracted from these data by A. Reed et al. (1998) for 1990-1998.

An estimate of hunting mortality of adults is provided by the harvest rate $(H)$, which is the ratio between the total number of adult birds harvested by recreational hunting and the total adult population at the start of the hunting season in autumn. In order to estimate the adult population size in autumn, we used the aerial photo census of the total population conducted every spring along the St. Lawrence River in Québec. To account for mortality occurring from spring to autumn, we multiplied the spring population size by the spring-to-autumn adult survival rate $(\hat{\phi}=0.96)$ estimated in this study. The harvest data do not include birds wounded or killed by hunters but not retrieved (crippling loss). This component of the harvest is poorly known. We assumed that $20 \%$ of geese shot were not retrieved, the value estimated for Mallards (Anderson and Burnham 1976). We therefore defined the kill rate $(K)$ as $1.25 H$.

Estimation of kill rate with this method assumes that both the population count and the harvest survey provide reliable estimates (Cooke et al. 2000), which we believe was true for Greater Snow Geese. First, the aerial photo census conducted in spring is an accurate total population count because the entire population at that time is restricted to a narrow strip along the St. Lawrence River in Québec (A. Reed et al. 1998). Second, sample sizes of the national harvest surveys have increased over the years, and thus the accuracy of harvest estimates has also increased. Third, the winter range of the Greater Snow Goose is restricted to the Atlantic Flyway and overlaps little with that of other snow goose populations; thus, the harvest estimate is unlikely to be contaminated much by other populations.

\section{Data analyses}

Neck band retention rate.-Survival estimates will be biased low by neck band loss. We therefore estimated neck band retention rate with geese recaptured during banding every year. We could estimate neck band retention rate because all marked birds also received a metal leg band. For 14 birds that were recaptured twice, we retained only the latest date of recapture to insure independence of the data. We used program SURVIV (White 1983) to estimate annual probabilities of retaining a neck band $k$ years after initial marking. Annual retention probability $\left(\theta_{j}\right)$ is defined as the probability that a bird alive with its neck band at time $j$ will retain its neck band from $j$ to $j+1$, given that the bird also survives. Among $N$ geese released and recaptured $k$ years after marking, the expected number of geese $(E)$ still with a neck band $\left(T_{k}\right)$ is estimated by the general model:

$$
E\left[T_{k}\right]=N \prod_{j=1}^{k} \theta_{j} .
$$

We modeled annual probability of neck band retention as a function of neck band age rather than calendar year because we believed that the principal cause of neck band loss was aging of the plastic (Hestbeck at al. 1990, Hestbeck 1994). In 1995, we changed the plastic type for a more UV-resistant plastic. We thus analyzed neck band retention rate separately for neck bands used during 1990-1994 (standard; all five co- 
horts pooled), and those used during 1995-1997 (UVresistant; three cohorts pooled). We tested reduced-parameter models in which annual retention rate was considered to be constant (i.e., independent of neck band age), equal between the two groups, or a function of neck band age (first group only). The best model was selected based on the Akaike Information Criterion (AIC; Lebreton et al. 1992).

Survival rate.-We estimated seasonal survival rates $(\phi)$ of adult females from summer 1990 to summer 1998 ( $k=25$ occasions; nine summers, eight winters, and eight springs), using the Cormack-Jolly-Seber (CJS) family of models (Cormack 1964, Jolly 1965, Seber 1965) and computer program SURGE (Lebreton et al. 1992). We first tested the fit of the CJS model to the data set using program RELEASE (Burnham et al. 1987). When examining individual contingency tables of goodness-of-fit tests, we transformed $\chi^{2}$ values into $z$ scores $\left(z=\sqrt{\chi^{2}}\right)$ for $2 \times 2$ tables with enough data, and assigned directionality based on the same table cell for all tests (i.e., the $z$ was positive if the observed value was greater than the expected one, and negative if the reverse was true). This increased the power of detecting consistent trends in the data (Lebreton et al. 1992). An overall $z$ test statistic across $n$ test statistics could be calculated as follows:

$$
z_{\text {pooled }}=\frac{\sum_{i=1}^{n} z_{i}}{\sqrt{n}} .
$$

Because we detected dependence in sighting probabilities (see Results: Goodness-of-fit tests of the CJS model), we used the modification to the CJS model proposed by Pradel (1993) for trap dependence, as both effects are statistically the same. This model accounts for short-term sighting dependence as follows: each time an individual is "recaptured" (i.e., seen), it is removed from its initial cohort and included in the cohort of "newly released" animals. This is equivalent to using the reduced $m$-array table of program RELEASE (Burnham et al. 1987) as input for the program SURGE (Lebreton et al 1992). The general model then becomes $\phi_{t} p_{t^{*} m}$, where $m$ is Markovian dependence in sighting probability $(p)$, and $t$ is time. This model is equivalent to a model with a two-age class structure on $p$, assuming no effect of true age on survival. This assumption was likely to be true because all females were marked as breeders ( $\geq 2$ yr old).

Even when accounting for short-term dependence in sighting probabilities (i.e., from time $i$ to $i+1$ ), the tests from RELEASE still indicated significant lack of fit, most likely due to dependence over a longer time interval (see Results: Goodness-of-fit tests of the CJS model). To account for that extra-binomial variation, we computed a conservative variance inflation factor, $\hat{c}$, which is the ratio of the residual $\chi^{2}$ goodness-of-fit tests of RELEASE (i.e., excluding the component 2.Ct, which is taken into account by the model with shortterm dependence in $p, \phi_{t} p_{t^{*} m}$ ) on its residual degrees of freedom, rdf. The $\sqrt{\hat{c}}$ was used to adjust the standard error of all parameters estimated, as recommended by Lebreton et al. (1992).

Starting with model $\phi_{t} p_{t^{*} m}$, a hierarchy of models sequentially constraining some parameters was fitted by the maximum likelihood method. For these analyses, we used a modified, unpublished version of SURGE 4.2 that takes into account unequal interval lengths, thus allowing us to test equality of monthly survival rate across seasons. We determined the most parsimonious list of parameters needed to model the data (i.e., the preferred model) with the AIC, and occasionally tested the significance of specific variables with likelihood ratio tests (LRT) (Lebreton et al. 1992, Burnham et al. 1995). AIC and LRT also had to be corrected for the $\hat{c}$. With the inflation factor, the AIC becomes the quasi-likelihood AIC (QAIC):

$$
\mathrm{QAIC}=\frac{\mathrm{DEV}}{\hat{c}}+2 \mathrm{np}
$$

where DEV is relative deviance and $n p$ is the number of parameters separately identifiable (Lebreton et al. 1992, Anderson et al. 1994). Similarly, the LRT corrected for $\hat{c}$ is treated as a $F$ test as follows:

$$
F_{\mathrm{df}, \mathrm{rdf}}=\frac{\mathrm{LRT} / \mathrm{df}}{\hat{c}} .
$$

This search for parsimonious models enhances the robustness of the conclusions, keeping only important parameters needed to describe the data, and providing precise estimates of those parameters.

Model notation.-Model notation follows Lebreton et al. (1992). Subscripts refer to factors or combinations of factors, with $(*)$ or without $(+)$ interactions, affecting each parameter. However, constraints imposed on a parameter sometimes differed among subgroups (e.g., different seasons or types of neck bands). In such cases, superscripts were used to distinguish subgroups.

Effect of hunting mortality on survival rate.-Our analysis of the effect of hunting on adult survival had two unique features compared to previous studies. First, we used a capture-recapture approach rather than band recoveries. Second, because we estimated survival rate on a seasonal basis, we could contrast the period when most hunting took place (the winter) to other periods of the year. Indeed, the bulk of the hunting season fell within our autumn-to-spring period, which extended from 15 October to 1 May. Some hunting mortality also occurred toward the end of our summerto-autumn period (i.e., the first two weeks of October in Québec), although more young than adults were harvested early in the hunting season (A. Reed et al. 1998).

Hunting mortality can be completely additive to natural mortality, completely compensated for by change in natural mortality below a certain threshold, or some- 
where in between (Anderson and Burnham 1976, Nichols 1991). Under the hypothesis of additive hunting mortality, winter survival should vary over years and should be a function of annual hunting mortality. In contrast, under the hypothesis that hunting is compensatory to natural mortality, winter survival should not be a function of annual variations in hunting mortality. Acceptance of a model with constant winter survival rate in the presence of variable hunting mortality would be evidence in favor of compensatory mortality (Burnham and Anderson 1984, Nichols 1991). If compensatory mortality is the outcome of a density-dependent process, then this hypothesis also predicts a positive relationship between hunting mortality and survival after the hunting season (Nichols 1991).

The relationship between the finite winter survival rate and hunting mortality under the hypothesis of complete additivity is a complex one. This is because both mortality risks are acting simultaneously; that is, if a bird dies from hunting then it is no longer "available" to die from natural causes, and vice versa. This relationship can only be investigated under the theory of competing instantaneous mortality risks (Anderson and Burnham 1976). However, a reasonable approximation of the relationship between finite winter survival rate $\left(\phi_{i}\right)$ in year $i$ and hunting mortality ( $K$ for kill rate) is given by the following linear equation:

$$
\phi_{i}=\phi_{0}+b K_{i}
$$

where $\phi_{0}$ is the winter survival rate in the absence of hunting, and $b$ is the slope of the linear relationship. It can be shown that under the hypothesis of complete additivity, $b \cong-\phi_{0}$ (Anderson and Burnham 1976). The relationship then becomes

$$
\phi_{i}=\phi_{0}-\phi_{0} K_{i}=\phi_{0}\left(1-K_{i}\right) .
$$

Using SURGE, we first tested for a significant linear relationship between the kill rate and winter survival (i.e., we built the relationship into the model without logit transformation). We then tested the hypothesis that the slope of this relationship was equal to the intercept, $-\phi_{0}$. For this analysis, the length of the winter interval was set to 1 and the lengths of the spring-tosummer and summer-to-autumn periods were expressed relative to the length of the winter period in months (3.5/6.5 and 2.5/6.5, respectively).

The proportion of variation in winter survival explained by the kill rate, which is akin to $r^{2}$, was estimated in two different ways. First, based on the ratio of differences in relative deviance (DEV) of various models as recommended by Agresti (1990),

$$
r_{\mathrm{DEV}}^{2}=\frac{\operatorname{DEV}\left(\phi_{0}+b K\right)-\operatorname{DEV}(t)}{\operatorname{DEV}(\text { constant })-\operatorname{DEV}(t)}
$$

where $\left(\phi_{0}+b K\right)$ is the kill rate dependent winter survival, $t$ is time-dependent winter survival, and constant is constant winter survival, other things being equal.

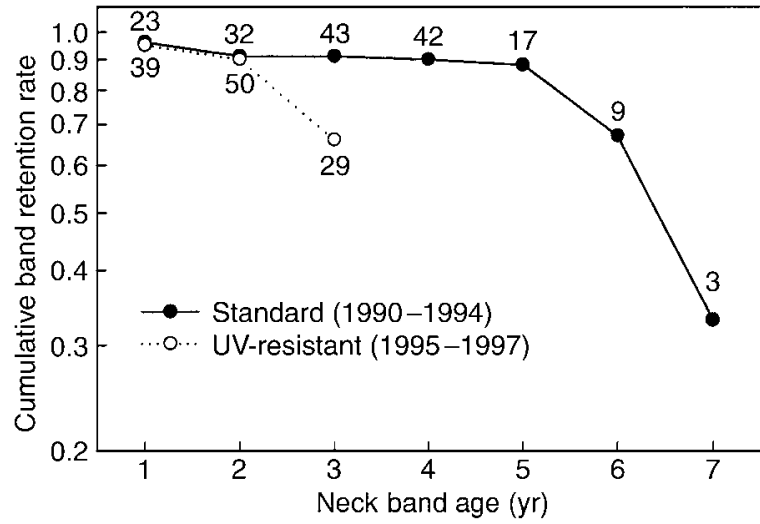

FIG. 1. Cumulative retention rate of neck bands by Greater Snow Geese according to age of the mark for standard neck bands (used from 1990 to 1994) and UV-resistant ones (used from 1995 to 1997). The sample size is provided for each data point.

This first measure is contaminated by sampling uncertainty and does not fully reflect the variation over time in parameters (Link 1999). Thus, the true variances over the years in monthly winter $(W)$ survival in the absence and in the presence of the relationship with $K$, denoted as $\sigma_{W}^{2}$ and $\sigma_{W / K}^{2}$, respectively, were estimated using random effect models (rand), based on a Weighted Least Squares approach (Lebreton 1995:1017) following K. P. Burnham (unpublished manuscript). The calculations were implemented in MATLAB. This led to a second measure of the proportion of variation in winter survival explained by the kill rate, which reflects variation in parameters corrected for sampling uncertainty:

$$
r_{\text {rand }}^{2}=1-\frac{\text { estimate of } \sigma_{W / K}^{2}}{\text { estimate of } \sigma_{W}^{2}}
$$

All statistical tests are two-tailed unless otherwise mentioned.

\section{RESULTS}

\section{Neck band retention rate}

We recaptured 287 neck-banded birds up to $7 \mathrm{yr}$ after initial marking, among which 36 had lost their neck band. If retention rate is independent of neck band age, the plot of cumulative retention rate on a log scale should be a straight line. There was evidence that the rate of neck band loss accelerated after $5 \mathrm{yr}$, and was higher in UV-resistant neck bands than in standard ones (Fig. 1). However, the preferred model had a constant retention rate (i.e., independent of age) that differed between the two groups of neck bands (Table 1: lowest AIC, model 6). A model with a negative quadratic relationship between retention rate and age for group 1 was the next best model (Table 1: model 5), but was not preferred, possibly due to small sample size beyond five years (Fig. 1). Under model 6, annual retention rate of neck bands with UV-resistant plastic (0.920 \pm 
TABLE 1. Analysis of neck band retention rate $(\theta)$ in female Greater Snow Geese (Chen caerulescens atlantica) according to age $(a)$ and type $(g)$ of neck band.

\begin{tabular}{|c|c|c|c|c|c|}
\hline \multirow[b]{2}{*}{ Model $\dagger$} & \multicolumn{3}{|c|}{ Goodness-of-fit statistics } & \multirow[b]{2}{*}{$\mathrm{np} \neq$} & \multirow[b]{2}{*}{ AIC } \\
\hline & $G$ & $\mathrm{df}$ & $P$ & & \\
\hline 1) $\theta_{a^{* g}}$ & & & & 10 & 47.57 \\
\hline 2) $\theta_{a}$ & 9.27 & 3 & 0.026 & 7 & 50.84 \\
\hline 3) $\theta_{a}^{g 1} \theta^{g 2}$ & 4.04 & 2 & 0.133 & 8 & 47.60 \\
\hline 4) $\theta_{\left(\beta_{0}+\beta_{1} a\right)}^{g 1} \theta^{g 2}$ & 9.27 & 7 & 0.234 & 3 & 42.58 \\
\hline 5) $\theta_{01}^{g\left(g_{0}+\beta_{1} a\right)} a^{2} \theta^{g 2}$ & 7.73 & 7 & 0.357 & 3 & 41.05 \\
\hline 6) $\theta_{g}$ & 8.90 & 8 & 0.351 & 2 & $\mathbf{4 0 . 4 7}$ \\
\hline 7) $\theta^{8}$ & 14.31 & 9 & 0.112 & 1 & 43.87 \\
\hline
\end{tabular}

Note: Boldface type denotes the selected model.

$\uparrow$ Explanation of abbreviations: $g 1$, Group 1, standard neck bands (used 1990-1994); g2, Group 2, UV-resistant neck bands (used 1995-1997).

$\ddagger$ Number of parameters estimated.

0.019 , mean $\pm 1 \mathrm{SE}$ ) was lower than that of standard neck bands $(0.963 \pm 0.008)$. When ignoring effects of both neck band age and type (Table 1: model 7), annual retention rate was estimated at $0.950 \pm 0.008$.

\section{Goodness-of-fit tests of the CJS model}

Because of the difference in retention rate between the two types of neck bands, we separated the data set in two groups (Group 1, 1990-1994 neck bands; Group 2, 1995-1997). Test 3 of RELEASE was not significant for either group, providing no evidence that newly marked birds behaved differently from previously marked ones in terms of resighting history (Table 2). This supported our assumption that, because of our extensive coverage of the staging area, no subgroups of marked birds have gone undetected, and that transient birds (e.g., Pradel et al. 1995) were not a problem in our study. However, most components of Test 2 were significant, indicating heterogeneity in sighting probabilities among individuals subsequently resighted (Table 2).

We examined Test 2.Ct by grouping individual tests according to season (spring to summer, summer to autumn, and autumn to spring). The spring to summer 2.Ct tests were balanced and the overall test was not significant in either group $(P>0.80$; Appendix A). In contrast, the overall summer to autumn 2.Ct tests were significant. This indicated a positive sighting dependence, i.e. birds seen in summer had a higher probability of being seen again in autumn than birds not seen in summer. The overall autumn to spring 2.Ct tests were also significant in each group (Appendix A). Although only one of the individual tests was significant, there was a consistent trend in all tests but one for a positive dependence in sighting probabilities between autumn and spring.

The goodness of fit of the model $\phi_{t^{*} g} p_{t^{*} m^{*} g}$, a model with two groups $(g)$ and full short-term (between consecutive seasons) dependence $(m)$ in $p$, is based on the sum of the goodness-of-fit statistics of Tests $3+2 . \mathrm{Cm}$ because Test 2.Ct accounts for short-term dependence.
This combined test was still significant for both groups (Group 1, $\chi^{2}=178.1$, df $=129, P=0.003$; Group 2, $\chi^{2}=57.0$, df $\left.=27, P=0.001\right)$ because of the Test 2.Cm. In order to correct for this overdispersion, we used an inflation factor in the remaining analysis (both groups combined, $\hat{c}=1.507)$.

We further examined for dependence in sighting probabilities over a longer time interval, i.e., from year to year within a season, because observation conditions were more similar within than between seasons. We compared birds that were seen at time $i$ and next seen again in the same season the following year (time $i+$ 3 ) vs. those not seen at time $i$ but next seen again at time $i+3$ (we extracted the information from the individual tables of Test 2.Cm). We then separated each individual test according to season (spring, summer, and autumn). We call this test 2.Cm*. The overall spring to spring 2. $\mathrm{Cm}^{*}$ test (Appendix B) showed a significant positive dependence in $p$ for Group 1 (i.e., birds seen in spring $i$ had a higher probability of being seen again in spring $i+1$ than those not seen in spring $i$ ) and a similar trend for Group 2. The overall summer to summer 2. $\mathrm{Cm}^{*}$ tests were not significant (Appendix B), although there was evidence for a weak negative dependence in $p$ between summer seasons. The overall autumn to autumn 2.Cm* tests were significant in each group (Appendix B) and showed a strong positive dependence in $p$ between autumn seasons.

In the following analysis, we attempted to control

TABLE 2. Goodness-of-fit tests of the Cormack-Jolly-Seber model obtained with RELEASE for the Greater Snow Goose resighting data on a seasonal basis.

\begin{tabular}{llrrc}
\hline \hline $\begin{array}{c}\text { Compo- } \\
\text { nent } \dagger\end{array}$ & Group & \multicolumn{1}{c}{$\chi^{2}$} & df & $P$ \\
\hline $3 . \mathrm{Sr}$ & 1 & 3.47 & 4 & 0.482 \\
$3 . \mathrm{Sm}$ & 1 & 2.95 & 3 & 0.399 \\
3 & 1 & 6.42 & 7 & 0.491 \\
$3 . \mathrm{Sr}$ & 2 & 1.86 & 2 & 0.396 \\
$3 . \mathrm{Sm}$ & 2 & 2.88 & 2 & 0.237 \\
3 & 2 & 4.73 & 4 & 0.316 \\
$3 . \mathrm{Sr}$ & $1+2$ & 5.33 & 6 & 0.503 \\
$3 . \mathrm{Sm}$ & $1+2$ & 5.83 & 5 & 0.323 \\
3 & $1+2$ & 11.16 & 11 & 0.430 \\
$2 . \mathrm{Ct}$ & 1 & 43.35 & 19 & 0.001 \\
$2 . \mathrm{Cm}$ & 1 & 171.69 & 122 & 0.002 \\
2 & 1 & 215.04 & 141 & 0.001 \\
$2 . \mathrm{Ct}$ & 2 & 12.38 & 7 & 0.089 \\
$2 . \mathrm{Cm}$ & 2 & 52.25 & 21 & 0.001 \\
2 & 2 & 64.64 & 28 & 0.001 \\
$2 . \mathrm{Ct}$ & $1+2$ & 55.73 & 26 & 0.001 \\
$2 . \mathrm{Cm}$ & $1+2$ & 223.94 & 143 & 0.001 \\
2 & $1+2$ & 279.68 & 169 & 0.001 \\
\hline
\end{tabular}

Note: Geese were marked either with standard (1990-1994, Group 1) or UV-resistant neck bands (1995-1997, Group 2).

$\dagger$ Component 3.Sr tests whether newly marked birds are more or less likely to be resighted at least once compared to previously marked ones. Component 3 .Sm tests whether newly marked birds differ from previously marked ones as to when they are resighted. Components 2 test whether birds seen on any given occasion are more or less likely to be seen at the next occasion (2.Ct) or any other subsequent occasion (2.Cm) compared to those not seen then. 
TABLE 3. Tests of the effects of type $(g)$ of neck band (standard or UV-resistant) on seasonal survival $(\phi)$ and sighting probabilities $(p)$, and of dependence in sighting probabilities $(m)$ in female Greater Snow Geese.

\begin{tabular}{|c|c|c|c|c|}
\hline Model $\dagger$ & $\mathrm{np}$ & DEV & QAIC & Description of models \\
\hline 1) $\phi_{t^{*} g} p_{t^{*} m^{*} g}$ & 95 & 30385.6 & 20353.0 & \\
\hline 2) $\phi_{t^{*}{ }_{g}} p_{t^{*} m}$ & 78 & 30447.2 & 20359.8 & $\begin{array}{l}\text { Absence of an effect of neck band type on sighting } \\
\text { probabilities }\end{array}$ \\
\hline 3) $\phi_{t^{*} g} p_{t^{*} g}$ & 64 & 30444.5 & 20330.0 & $\begin{array}{l}\text { Absence of full short-term dependence in sighting } \\
\text { probabilities }\end{array}$ \\
\hline 4) $\phi_{t^{*} g} p_{t+g}$ & 57 & 30469.0 & 20332.5 & $\begin{array}{l}\text { Additive effect of neck band type on sighting proba- } \\
\text { bilities }\end{array}$ \\
\hline 5) $\phi_{t^{*} g} p_{t+g+g U}$ & 58 & 30449.1 & 20321.1 & $\begin{array}{l}\text { Additive effect of neck band type on sighting proba- } \\
\text { bilities different in summer }(g U)\end{array}$ \\
\hline 6) $\phi_{t+g} p_{t+g+g U}$ & 51 & 30460.7 & 20314.8 & Additive effect of neck band type on survival rate \\
\hline 7) $\phi_{t} p_{t+g+g U}$ & 50 & 30462.3 & 20313.9 & $\begin{array}{l}\text { Absence of an effect of neck band type on survival } \\
\text { rate }\end{array}$ \\
\hline 8) $\phi_{t} p_{t+m U A+m A P+m P P+m A A+m U U+g+g U}$ & 55 & 30410.0 & 20289.1 & $\begin{array}{l}\text { Additive effect of selected dependence on sighting } \\
\text { probabilities }\end{array}$ \\
\hline 9) $\phi_{t} p_{t+m U A+m A P+m P P+m A A+g+g U}$ & 54 & 30410.8 & 20287.7 & $\begin{array}{l}\text { Absence of summer-to-summer dependence }(m U U) \text { in } \\
\text { sighting probabilities }\end{array}$ \\
\hline 9a) $\phi_{t+g} p_{t+m U A+m A P+m P P+m A A+g+g U}$ & 55 & 30409.2 & 20288.6 & $\begin{array}{l}\text { Additive effect of neck band type on survival rate in } \\
\text { presence of selected dependence in sighting proba- } \\
\text { bilities }\end{array}$ \\
\hline
\end{tabular}

Notes: Boldface type denotes the selected model. Abbreviations: np, number of parameters; DEV, relative deviance; QAIC, Akaike Information Criterion corrected for $\hat{c}$.

$\dagger U$, summer; $A$, autumn; $P$, spring. Selected short-term dependence in sighting probabilities: $m U A$, summer to autumn; $m A P$, autumn to spring. Long-term dependence in sighting probabilities: $m P P$, spring to spring; $m U U$, summer to summer; $m A A$, autumn to autumn.

for this between-year, within-season dependence in sighting probabilities. Controlling for this long-term dependence in $p$ should, in theory, reduce the inflation factor calculated previously. However, there is no simple goodness-of-fit test for such a model. Therefore, the $\hat{c}$ value as previously calculated was retained in subsequent analyses, although this value may be too high in models in which we account for long-term dependence in $p$. This should make our comparisons between models slightly more conservative.

\section{Neck band type effects}

Over the period 1990-1997, we neck-banded 3890 geese (108-761 annually), and cumulated 13657 resightings (excluding repeats within the same season) up to summer 1998. Starting with the general model $\phi_{t^{*} g} p_{t^{*} m^{*} g}$ (full short-term dependence in sighting probabilities), we attempted to remove the group effect (i.e., neck band type) on $p$, but this model provided a poorer fit to the data (Table 3: model 2 vs. 1). However, the model with full short-term dependence on $p\left(\phi_{t^{*} g} p_{t^{*} m^{*} g}\right)$ was over-parametized because a model without any dependence was preferred (model 3 vs. 1). We thus proceeded with this model to test further the group effects on $\phi$ and $p$.

The difference in sighting probability between the two groups was not a simple additive effect (i.e., a constant difference in $p$ between new and old neck bands; Table 3: model 4 vs. 3). A possible explanation was the difference in sampling methods between seasons. In spring and autumn, we only had resightings, whereas in summer we had a mixture of resightings and physical recaptures. To examine this possibility, we added a specific interaction term for the summer period to the additive model, and this model was preferred (model 5 vs. 3). Based on the lower retention rate of the new neck bands, we anticipated that a model with an additive group effect on survival (i.e., a constant difference in $\phi$ between the two groups) should fit the data better. However, a model without group effect on survival (i.e., equal survival rate between the two groups) provided the most parsimonious fit to the data (Table 3: model 7). Therefore, we used the retention rate obtained when ignoring neck band age and type effects $(0.95)$ to correct $\hat{\phi}$ for neck band loss.

\section{Sighting-dependence effects}

We examined whether the specific sighting-dependence effects identified from the goodness-of-fit tests (positive dependence in $p$ from summer to autumn $[m U A]$, autumn to spring $[m A P]$, spring to spring $[m P P]$, and autumn to autumn $[m A A]$ and negative dependence from summer to summer $[m U U])$ could improve the model $\phi_{t} p_{t+g+g U}($ model 7$)$. Each of these effects was considered additive across years. This model (Table 3: model 8) was preferred by a wide margin in QAIC over model 7. We then dropped each of the five dependence effects on $p$ one at a time to test their importance. All of them were significant except for the summer-to-summer dependence in sighting probabilities $\left(F_{1,151}=0.58, P>0.1\right)$, which was not retained (Table 3: model 9).

Estimated probabilities of sighting marked birds generally increased throughout the study in spring and autumn, and toward the end of the study in summer (Fig. 2). In spring, the probability of seeing a bird was in- 

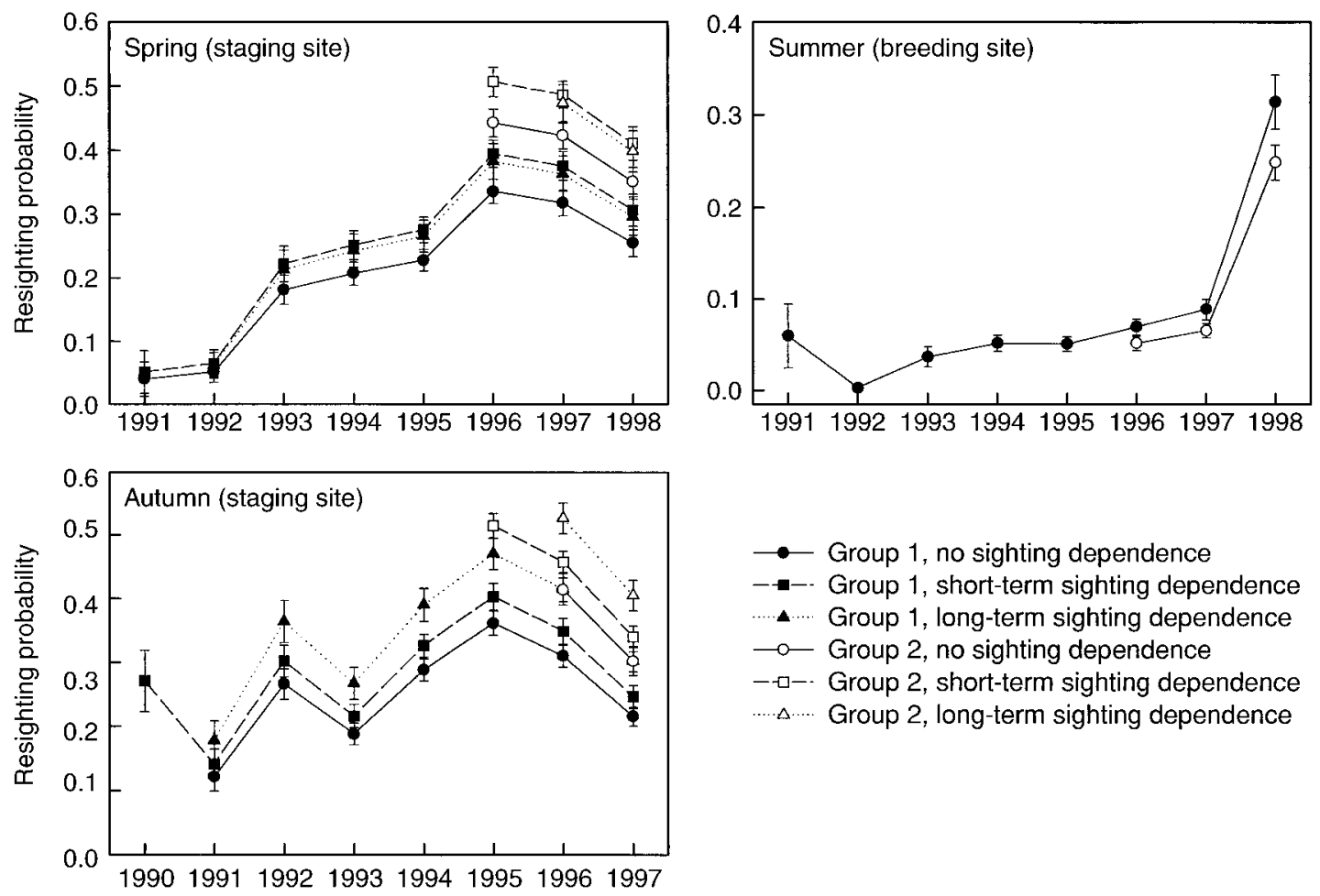

FIG. 2. Probability of sighting ( $p$ ) of female Greater Snow Geese according to year and season in the absence of dependence in sighting probabilities (birds not last seen in the previous season or in the same season in the previous year); in the presence of short-term sighting dependence (birds last seen in the previous season); and in the presence of long-term sighting dependence (birds last seen in the same season in the previous year). Probabilities were estimated using model 15 in Table 4 . Group 1 wore standard neck bands (used 1990-1994); Group 2 wore UV-resistant neck bands (used 1995-1997). Values are means $\pm 1 \mathrm{SE}$.

creased by $15-20 \%$ if that bird had been seen in the previous period (autumn, short-term sighting dependence), or had been last seen in the previous spring (long-term sighting dependence). In autumn, the longterm was much stronger than the short-term sighting dependence as the probability of seeing a bird was increased by $30-40 \%$ if it had been last seen in the

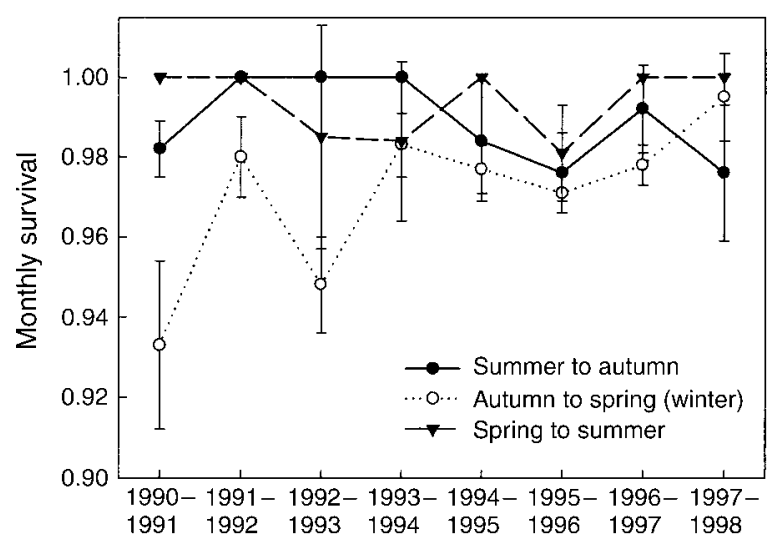

FIG. 3. Annual variation in monthly survival rate of female Greater Snow Geese in different seasons, estimated with model 9 in Table 4 . Values are means \pm 1 SE. previous autumn, but only $10-15 \%$ if it had been seen in the previous period (summer). The group effect on sighting probabilities was also obvious. New neck bands were more likely to be resighted than older ones in both spring and autumn, but not in summer (Fig. 2).

Attempts to further reduce the number of parameters associated with sighting probabilities (e.g., by constraining time-specific variations in $p$ on an index of observation effort) failed. A model with group effect on $\phi$ in the presence of sighting dependence on $p$ (Table 3: model 9a) was again not preferred. For all remaining models, sighting probabilities were modeled as $p_{t+m U A+m A P+m P P+m A A+g+g U}$.

\section{Seasonal variations in survival rate}

Examination of temporal variations in monthly survival rate suggested that winter survival was lower and more variable than at other seasons (Fig. 3); these trends were confirmed by the following analysis. A model with survival rates equal from spring to summer $(P)$ and summer to autumn $(U)$, but different in winter, $W$ (Table 4: model 11) was preferred over a model (10) with additive effects of year $(y)$ and season $(s)$, or a model (12) with equal survival rate across all seasons. This confirmed that mortality risk was higher in winter 
TABle 4. Tests of the effect of season $(s)$, year $(y)$, and hunting (kill rate, $K$ ) on female Greater Snow Goose survival rate.

\begin{tabular}{|c|c|c|c|c|}
\hline Model & $\mathrm{np}$ & DEV & QAIC & Description of models \\
\hline 9) $\phi_{t}$ & 54 & 30410.8 & 20287.7 & From Table 3 \\
\hline 10) $\phi_{y}$ & 40 & 30418.9 & 20265.1 & Additive effect of year $(y)$ and season $(s)$ on survival rate \\
\hline 11) $\phi_{y}^{P U} \phi_{y}^{W}$ & 39 & 30419.1 & 20263.2 & $\begin{array}{l}\text { Equality of survival rate between spring to summer }(P) \text { and sum- } \\
\text { mer to autumn }(U)\end{array}$ \\
\hline 12) $\phi_{y}$ & 38 & 30425.5 & 20265.4 & Equality of survival rate in all seasons \\
\hline 13) $\phi^{P U} \phi^{W}$ & 32 & 30455.5 & 20273.4 & Constant survival rate in all seasons \\
\hline 14) $\phi_{y}^{P U} \phi^{W}$ & 39 & 30429.1 & 20269.8 & Constant survival rate between autumn to spring ( $W$, winter) \\
\hline 15) $\phi^{P U} \phi_{y}^{W}$ & 39 & 30419.9 & 20263.7 & $\begin{array}{l}\text { Constant survival rate between spring to summer }(P) \text { and summer } \\
\text { to autumn }(U)\end{array}$ \\
\hline 16) $\phi^{P U}\left(\phi_{0}+b K_{y}\right)^{W}$ & 33 & 30452.9 & 20273.7 & Autumn to spring ( $W$, winter) survival dependent on kill rate $(K)$ \\
\hline 17) $\phi_{0}+b K_{y}$ & 32 & 30453.0 & 20271.7 & $\begin{array}{l}\text { Natural mortality constant and equal in all seasons }\left(\phi_{0}=\phi^{P U}\right) \text {, } \\
\text { and winter }(W) \text { survival dependent on kill rate }(K)\end{array}$ \\
\hline 18) $\phi$ & 31 & 30460.4 & 20274.6 & Constant survival rate in all years and seasons \\
\hline 19) $\phi_{y}^{P} \phi^{U} \phi_{y}^{W}$ & 40 & 30419.1 & 20265.2 & Constant survival rate summer to autumn $(U)$ \\
\hline 20) $\left(\phi_{0}+b K_{y}\right)^{P} \phi^{U} \phi_{y}^{W}$ & 41 & 30418.9 & 20267.1 & $\begin{array}{l}\text { Spring to summer }(P) \text { survival rate dependent on previous winter } \\
\quad \text { kill rate }(K)\end{array}$ \\
\hline 21) $\phi^{P} \phi^{U} \phi_{y}^{W}$ & 40 & 30419.5 & 20265.5 & $\begin{array}{l}\text { Constant survival rate spring to summer }(P) \text { and summer to au- } \\
\text { tumn }(U)\end{array}$ \\
\hline
\end{tabular}

Notes: For all models, sighting probability is modeled as $p_{t+m U A+m A P+m P P+m A A+\mathrm{g}+\mathrm{gU}}$. Other notation is as in Table 3. Boldface type denotes the selected model.

than in other seasons. Models with winter survival constant over the years (Table 4: models 13 or 14) were not retained, but a model (15) with constant survival rate for periods other than winter (i.e., spring to summer and summer to autumn) was preferred because its QAIC was only 0.5 units greater than model 11 with the same number of parameters. This confirmed that monthly survival was variable across years in winter, but showed little annual variation in spring and summer.

Based on the preferred model (Table 4: model 15), the monthly survival rate for the two periods extending from spring to autumn ( $5.5 \mathrm{mo})$ was estimated at 0.989 (Table 5). Correcting for neck band loss, this gave an overall survival rate for this period of 0.963 (assuming that the neck band retention rate was constant throughout the year). Point estimates of monthly winter survival ranged from 0.936 to 0.993 . Precision on survival rate estimates was good except in the first year of the study, when there were low sighting rates (Fig. 2).

TABLE 5. Mean values (with $1 \mathrm{SE}$ in parentheses) for monthly survival rate from spring to summer and summer to autumn $\left(\phi^{P U}\right)$, monthly survival from autumn to spring $\left(\phi^{W}\right.$, winter), and annual survival rate corrected for neck band loss ( $\phi$ corr) in adult female Greater Snow Geese (from model 15 in Table 4).

\begin{tabular}{|c|c|c|c|}
\hline Year & Monthly $\phi^{P U}$ & Monthly $\phi^{W}$ & Annual $\phi$ corr \\
\hline $1990-$ & & $0.936(0.021)$ & $0.642(0.095)$ \\
\hline 1991-1992 & & $0.989(0.010)$ & $0.924(0.056)$ \\
\hline 1992-1993 & & $0.951(0.008)$ & $0.714(0.039)$ \\
\hline 1993-1994 & & $0.984(0.006)$ & $0.893(0.032)$ \\
\hline 1994-1995 & & $0.977(0.005)$ & $0.849(0.027)$ \\
\hline 1995-1996 & & $0.967(0.004)$ & $0.795(0.022)$ \\
\hline 1996-1997 & & $0.979(0.004)$ & $0.859(0.024)$ \\
\hline 1997-1998 & & $0.993(0.008)$ & $0.945(0.051)$ \\
\hline Mean & $0.989(0.003)$ & 0.972 & $0.828(0.048)$ \\
\hline
\end{tabular}

Combining the estimates for the three periods and correcting for neck band loss, we estimated that the annual survival rate of adult females was $0.828 \pm 0.048$ (mean $\pm 1 \mathrm{SE}$ ), ranged from 0.642 to 0.945 .

\section{Effect of hunting on survival}

From 1990 to 1997, the estimated kill rate of adult Greater Snow Geese ranged from $4.7 \%$ to $11.8 \%$. Plotting the annual winter survival (from Table 4: model 15) against the kill rate showed an inverse relationship (Fig. 4), suggesting that hunting mortality was additive to natural mortality. To formally test this relationship, we modeled it as $\phi^{P U}\left(\phi_{0}+b K_{y}\right)^{W}$. This model (16) had a higher QAIC than one with time-dependent winter survival (Table 4, model 15). The slope of the relationship was estimated at -1.11 but did not differ significantly from 0 because of a wide confidence in-

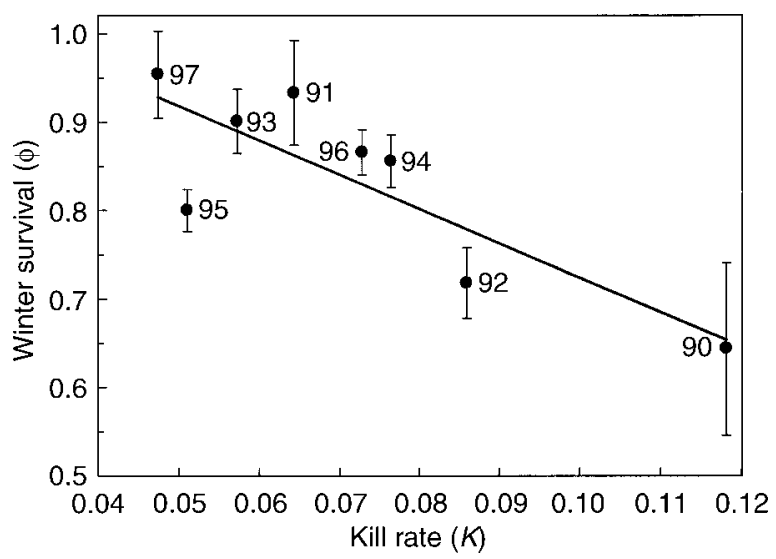

FIG. 4. Relationship between winter survival $(\phi)$ of female Greater Snow Geese and adult kill rate $(K)$. Survival was obtained from model 15 in Table 4 . The year is given beside each data point, which represents mean \pm 1 SE. 
TABLE 6. Estimation of the intercept $\left(\phi_{0}\right)$ and the slope $(b)$ of the relationship between hunting mortality $(K$, kill rate) and winter survival (autumn to spring, $W$ ) in female Greater Snow Geese.

\begin{tabular}{|c|c|c|c|c|c|c|}
\hline \multirow[b]{2}{*}{ Model } & \multicolumn{2}{|c|}{$\phi^{P U}$} & \multicolumn{2}{|c|}{$\phi_{0}$} & \multicolumn{2}{|r|}{$b$} \\
\hline & Estimate & $95 \% \mathrm{CI}$ & Estimate & $95 \% \mathrm{CI}$ & Estimate & $95 \% \mathrm{CI}$ \\
\hline $\begin{array}{l}\text { 16) } \phi^{P U}\left(\phi_{0}+b K_{y}\right)^{W} \\
\text { 17) } \phi_{0}+b K_{y}\end{array}$ & 0.928 & $0.899,0.957$ & $\begin{array}{l}0.918 \\
0.926\end{array}$ & $\begin{array}{l}0.801,1.034 \\
0.883,0.969\end{array}$ & $\begin{array}{l}-1.111 \\
-1.207\end{array}$ & $\begin{array}{l}-2.842,0.620 \\
-2.304,-0.110\end{array}$ \\
\hline
\end{tabular}

Note: Values of $\phi$ are expressed over the length of the winter interval (6.5 mo) and are not corrected for neck band loss; $\phi^{P U}$ is the monthly survival rate from spring to summer and summer to autumn.

terval (Table 6). Winter survival in the absence of hunting mortality, $\phi_{0}$ (considering only natural mortality), was very similar to survival during the rest of the year $\left(\phi^{P U}\right)$, taking into account the unequal interval lengths. A model in which $\phi^{P U}$ was set equal to $\phi_{0}$ (the intercept of the relationship between $\phi^{W}$ and $K$ ) was easily accepted (model 17 vs. $16, F_{1,151}=0.03, P>0.1$; Table 4 ), showing that survival in the absence of hunting was equal throughout the year. Under this simple model, $b$ was estimated at -1.21 and significantly differed from 0 (Table 6). This value was reasonably close to $-\phi_{0}$ $(-0.926)$, the value expected under the hypothesis of complete additivity of hunting mortality.

Estimates of the variance over time in winter monthly survival in the absence vs. presence of a relationship with kill rate were $\sigma_{W}^{2}=2.235 \times 10^{-4}$ vs. $\sigma_{W / K}^{2}=1.215$ $\times 10^{-4}$. The proportion of the variability in survival explained by the kill rate once the sampling uncertainty has been accounted for was thus $r_{\text {rand }}^{2}=0.456$. As expected, this estimate was higher than the deviancebased estimate $\left(r_{\mathrm{DEV}}^{2}=0.184\right)$. The estimated relationship with kill rate in the model with a random component added to the relationship became

$$
\phi^{W}=\phi_{0}-0.3317( \pm 0.1751) K .
$$

These estimates made it possible to test for the additive mortality when correcting for sampling uncertainty, a model slightly more general than model 17 (Table 4). The observed slope differed significantly from $0(z=$ $-0.3317 / 0.1751=-1.89, P<0.05$, one-tailed test). The theoretical slope equal to $-\phi_{0}$ for additive mortality is here relative to the monthly kill rate, which is approximately $K_{\text {monthly }}=K_{\text {annual }} / 6.5$. With monthly $\phi_{0}$ close to 1 , the expected slope in the absence of compensation is thus $1 / 6.5=0.1538$. The observed value did not differ from this theoretical value $(z=[-0.3317$ $-(-0.1538)] / 0.1751=-1.02, P>0.1)$. This again suggests that hunting mortality is largely additive to natural mortality during winter in adult female Greater Snow Geese.

The prediction by the compensatory mortality hypothesis of a positive relationship between hunting mortality and survival after the hunting season (spring to summer) was not upheld. Models in which springto-summer survival was either time dependent (model 19 ) or constant (model 21) were both preferred to model 20, in which survival was dependent on the previous winter kill rate (Table 4: model 20 vs. $19, F_{1,151}=0.13$,
$P>0.1 ;$ model 20 vs. $\left.21, F_{1,151}=0.40, P>0.1\right)$. Furthermore, the relationship had a negative trend, the opposite of the predicted direction.

\section{DisCUSSION}

\section{Seasonal and annual survival rates}

Much of life-history theory assumes that natural mortality risk varies throughout the annual cycle of an animal in response to activities such as reproduction or migration. However, we found little evidence that natural mortality varies seasonally in Greater Snow Geese. In many ground-nesting birds, mortality risk during the breeding season is thought to be high. For instance, Sargeant et al. (1984) reported a high predation rate on incubating females in several duck species, but the importance of this mortality risk in the annual cycle is poorly known. Blohm et al. (1987) provided weak evidence that summer survival of female Mallards was inversely related to the nesting effort of the population, lending support to the hypothesis that breeding represents an additional mortality risk. Although incubating female snow geese are sometimes killed on the nest by predators (G. Gauthier, unpublished observation), we found little evidence that breeding represented a significant additional mortality risk during the summer. Francis and Cooke (1992) did not find sex-specific differences in annual survival rate in Lesser Snow Geese, although this may not preclude differences in survival between males and females at certain periods of the year, such as breeding (Schmutz and Ely 1999). High survival in summer compared to other times of the year was also found in female Brant (Branta bernicla; Ward et al. 1997) and Barnacle Geese (Owen 1982).

Theories on the evolution of migratory behavior in birds assume that long-distance migration entails a survival cost (Greenberg 1980, Alerstam 1990). Evidence supporting this assumption is largely indirect (Nichols 1996) and includes: (1) the occasional observation of mass mortality during migration, usually following extreme weather conditions (Greenberg 1980); (2) an inverse relationship between annual survival rate and migration distance, with evidence in waders (Pienkowski and Evans 1985) and Wood Ducks (Aix sponsa; Nichols and Johnson 1990), but not in British passerines (O’Connor 1985) and Mallards (Hestbeck et al. 1992); and (3) increased mortality rate of young in their first 
autumn migratory flight compared to adults (Owen and Black 1989, van der Jeugd and Larsson 1998). Our results did not indicate a significant survival cost of migration in adult Greater Snow Geese. The spring migratory flight $(3000 \mathrm{~km})$ was included with breeding activity in the spring-to-summer period, but the shorter summer-to-autumn period was mostly limited to the autumn migratory flight, along with the short fledging phase. Yet, monthly survival rate during these two periods was similar to the winter survival rate once hunting mortality was removed. In Brant, Ward et al. (1997) also found higher survival during migration than during the rest of the year. In contrast, there was some evidence that the mortality rate was highest during the autumn migration in Barnacle Geese (Owen 1982, Owen and Black 1991), but no estimates of survival during and outside the migration period are available. Therefore, we concur with Nichols (1996) that appropriate capture-recapture methodologies are needed for a critical evaluation of the assertion that migration entails a survival cost in long-distance migrant birds.

The annual survival rate of adult female Greater Snow Geese (mean 0.83, range 0.64-0.95) is relatively high for a hunted goose population. In Lesser Snow Geese (Chen caerulescens caerulescens), the annual survival rate of the mid-continent population increased from 0.78 to 0.88 for the period 1970-1987 (Francis et al. 1992b) and was between 0.89 and 0.94 during 1990-1994, a period of low hunting mortality (Cooke et al. 2000). Annual survival rates were lower in the Western Arctic and Wrangel Island populations for the period 1987-1989 (0.80 and 0.69, respectively, Hines et al. 1999). In absence of hunting, we estimated that the average annual survival rate of Greater Snow Geese would have been 0.913 during the period 1990-1998, which suggests that $\sim 50 \%$ of annual mortality was due to hunting. These values are similar to Lesser Snow Geese, for which Francis et al. (1992a) estimated that natural mortality was $8 \%$ and that hunting accounted for $\sim 58 \%$ of total mortality. Based on a review of several population studies, Ebbinge (1991) estimated natural mortality in geese at $5.2 \%$ to $9.7 \%$, a range compatible with the estimated natural mortality rate found in this study.

\section{Effect of hunting on survival}

The period of lowest monthly survival was in winter, when most hunting took place. Our analysis provided direct evidence that hunting mortality was largely additive, with kill rate explaining $\sim 46 \%$ of the variation in winter survival. This may be a minimum value for several reasons. First, kill rate is estimated from hunter surveys in both the United States and Canada, and there are errors associated with these estimates (Hestbeck 1994, Cooke et al. 2000). Second, a fraction of hunting mortality was excluded from our winter survival estimate (the first two weeks of October in Québec). Third, the variation in kill rate during this 8 -yr study
(4.7-11.8\%) was relatively small, which magnifies the relative error on kill rate. Fourth, kill rate estimates exceeded $8 \%$ in only two of the eight years, and the highest value $(11.8 \%)$ occurred in the first year of the study when sample sizes were lowest and imprecision on survival rate estimates was greatest.

Estimating the survival rate on a seasonal basis allows a further test of the compensatory mortality hypothesis. Such a test is not possible when survival is estimated on an annual basis. The notion of compensatory mortality implies that natural mortality is, to some extent, density dependent during some periods of the year. Because density-dependent effects should be reduced following winters of heavy hunting mortality, this hypothesis predicts a positive relationship between hunting mortality and survival after the hunting season (Nichols 1991). We found no evidence for that. Even though the Greater Snow Goose population doubled during the course of this study (from 368000 birds in 1990 to 740000 in 1998; A. Reed et al. 1998), we believe that density-dependent effects on adult survival are unlikely. In mid-continent Lesser Snow Geese, with a population at least five times larger than Greater Snow Geese, Cooke et al. (2000) reported an increase in adult survival during a 24-yr period characterized by continuous population growth. The absence of density-dependent effects on adult survival contrasts with juvenile survival, in which there is good evidence for density-dependent effects in snow geese (Cooch and Cooke 1991).

In Mallards, Anderson and Burnham (1976) and Burnham and Anderson (1984) concluded that hunting mortality was largely compensated for by a change in natural mortality. In their study, annual kill rate estimates ranged from $10 \%$ to $26 \%$, and the mean annual survival rate was estimated as 0.56 in females and 0.64 in males. However, in a more recent analysis, Smith and Reynolds (1992) rejected both the completely compensatory and completely additive models for Mallards. In Black Ducks (Anas rubripes), Francis et al. (1998) concluded that hunting mortality was additive when the harvest was high, but compensatory when the harvest rate was reduced. In contrast, several studies suggested that hunting mortality is mostly additive in geese (Francis et al. 1992b, Rexstad 1992, Hestbeck 1994, Schmutz and Ely 1999). In some cases, this conclusion was solely based on comparisons of survival rate during periods of high and low harvest. Rexstad (1992) tested for a functional relationship between hunting mortality and survival rate in Canada Geese and found evidence for additivity. However, because kill rate in his study was very high (mean 33\%; range $18-43 \%$ ), he could not determine whether hunting mortality was truly additive or whether the threshold for compensation had been exceeded (Anderson and Burnham 1976). Our study showed that hunting mortality can also be additive at much lower kill rate values (5$12 \%)$. Hunting mortality is additive in adult female 
geese, even at a low harvest rate, in contrast to ducks, in which it is often compensatory to natural mortality. This fact supports the prediction of Anderson and Burnham (1976) that long-lived species with low natural mortality should be less able to compensate for an additional source of mortality such as hunting.

\section{Dependence in sighting probabilities}

Although resightings of marked animals should be less prone to problems of dependence in $p$ than are physical captures, the strongest dependence effects were detected in the two seasons (spring and autumn) when data came solely from resightings. We believe that the behavior of the birds and heterogeneity in site fidelity may account for the sighting dependence. Newly marked birds were more likely to be successful breeders (i.e., females with young) because failed breeders and nonbreeders leave the study site to molt, or molt too early to be captured in late summer (G. Gauthier, unpublished observation). Because adults accompanied by young tend to stay for a longer period on the staging areas in autumn than those without young (Maisonneuve and Bédard 1992), this could increase their chance of being seen and explain the positive summer-to-autumn dependence in sighting probabilities. Furthermore, family bonds last up to one year in geese (Prevett and MacInnes 1980, Black and Owen $1989 b$ ); and adults accompanied by young are dominant over other birds and tend to be at the edge of flocks (Teunissen et al. 1985, Black and Owen 1989a). Because marked birds at the edge of flocks are more easily observed than those within a flock, this factor could also contribute to the summer-to-autumn and autumn-to-spring dependence in sighting probabilities.

Maisonneuve and Bédard (1993) suggested that staging Greater Snow Geese did not show site fidelity to specific areas of the St. Lawrence Estuary in autumn. However, the long-term sighting dependence (between years, within the same season) suggests that geese may show faithfulness to specific areas of the St. Lawrence River in spring and autumn. Site fidelity would result in sighting dependence, because observations were consistently conducted at the same sites along the St. Lawrence River. Site fidelity outside the breeding season is common in birds and has been shown in staging and wintering geese (Raveling 1979, A. Reed et al. 1989, E. T. Reed et al. 1998). A stronger long-term sighting dependence in autumn than in spring may be a consequence of hunting, which tends to concentrate geese in a few refuges or sanctuaries (Maisonneuve and Bédard 1993).

Differential behavior according to breeding success and site fidelity, the likely sources of sighting dependence in our study, are widespread phenomena in birds. Thus, dependence in sighting probabilities may be a common problem of studies using a sampling design similar to ours (e.g., Ebbinge et al. 1991, Schmutz et al. 1994, Ward et al. 1997). In an earlier analysis of our data set with a smaller number of years (spring 1991 to autumn 1996), Gauthier and Menu (1997) did not account for sighting dependence. Their estimate of annual survival rate was lower than in this study $(0.77$ vs. 0.83), and monthly survival rate was lower from spring to summer than from autumn to spring, in contrast to the present analysis. Thus, failure to account for dependence in sighting probabilities may result in a biased survival rate and may lead to erroneous conclusions (e.g., lower summer than winter survival). Because we used an adequate decomposition of the overall goodness-of-fit statistics into interpretable components, those in RELEASE (Burnham et al. 1987) plus the trap-dependence components of Pradel (1993), we eliminated much of this lack of fit by incorporating specific structural features in our general model. Therefore, our estimate of overdispersion was not overestimated as it would have been by using an overall goodness-of-fit statistic (e.g., by bootstrapping), which would have led to a less specific general model.

Combining observations of marked individuals made at staging sites distant from the breeding site where marking occurs has several advantages. This not only allows estimation of survival on a seasonal basis, but also provides more robust estimates of annual survival. For instance, mixing of individuals occurring during migration should allow estimation of survival rates that are not confounded by permanent emigration from the breeding area (i.e., "local" survival). If individuals are more concentrated at the staging sites than at the breeding site, as was the case here, this could increase sighting rates and, hence, precision of survival estimates.

\section{Neck band type}

Correcting survival estimates with mark retention rate was essential in our study, as the assumption of no mark loss was violated. An additional problem was the higher loss rate of the UV-resistant neck bands, compared to the standard type. However, survival rate did not differ between the two groups of neck bands, even though losing a mark is equivalent to the death of an individual. Because we used the standard bands from 1990 to 1994 and the UV-resistant ones afterward, bands of the former type were older during the period when both types were present in the population (19951998). If there is a slight increase in loss rate with age of the mark, as suggested by our analysis and by Johnson et al. (1995), this effect may cancel out the higher loss rate of UV-resistant bands compared to standard ones. Differences in plastic type or the younger age of UV-resistant neck bands may explain their higher sighting probabilities compared to standard bands. As neck bands age, the engraved codes slowly fade away, making them more difficult to read under poor visibility or increasing distance. The similar sighting probabilities between the two groups during the summer may have resulted because a large proportion of the data then came from physical recaptures, bright or faded codes 
having an equal chance of being read when a bird is in hand.

Because we could not detect differences in survival rate between the two types of neck bands, we used the neck band retention rate estimated for both groups combined. Although there may still be some undetected heterogeneity in the data due to a complex interaction between neck band age and type, the proportion of marked individuals with old neck bands ( $>5 \mathrm{yr}$ old) is small in the data set due to their disappearance through death. Another problem related to neck bands is their possible negative effect on survival (Schmutz and Morse 2000). However, we showed that neck bands had no effects on the survival rate of Greater Snow Geese (Menu et al. 2000).

\section{Conclusion}

The accumulation of resightings during three different periods of the annual cycle allowed precise estimation of survival rate on a seasonal basis with little confounding effect of permanent emigration. The absence of seasonal variations in natural mortality suggests that the lengthy migratory flights (3000 km each) and breeding activity did not entail a survival cost for adult female Greater Snow Geese. Hunting mortality was the only source of variation in annual survival rate, and was additive to natural mortality even at a low kill rate. This is probably a general feature of long-lived species because their low and relatively constant natural mortality rate does not allow them to compensate for an additional source of mortality such as hunting.

\section{ACKNOWLEDGMENTS}

This project was funded by the Arctic Goose Joint Venture of the Canadian Wildlife Service, the Natural Science and Engineering Research Council of Canada, and the Fonds pour la Formation des Chercheurs et l'Aide à la Recherche of the Québec Government (FCAR). We thank the Polar Continental Shelf Project for generously providing logistic support in the Arctic, and the Pond Inlet Hunter and Trapper Association for allowing us to work on Bylot Island. We acknowledge the assistance of a large number of people in banding and resighting geese over the years, and especially Austin Reed and Gérald Picard. We also thank Jim Nichols, Jean-François Giroux, Charles Francis, and Brett Sandercock for detailed comments on an earlier version of the manuscript. G. Gauthier is grateful to the Centre d'écologie fonctionnelle et évolutive of Montpellier for providing working space during the writing of this paper.

\section{Literature Cited}

Agresti, A. 1990. Categorical data analysis. John Wiley, New York, New York, USA.

Alerstam, T. 1990. Bird migration. Cambridge University Press, Cambridge, UK.

Anderson, D. R., and K. P. Burnham. 1976. Population ecology of the mallard. VI. The effects of exploitation on survival. U.S. Fish and Wildlife Service Resource Publication 128.

Anderson, D. R., K. P. Burnham, and G. C. White. 1994. AIC model selection in overdispersed capture-recapture data. Ecology 75:1780-1793.

Black, J. M., and M. Owen. 1989a. Agonistic behaviour in barnacle goose flocks: assessment, investment and reproductive success. Animal Behaviour 37:199-209.

Black, J. M., and M. Owen. 1989b. Parent-offspring relationships in wintering barnacle geese. Animal Behaviour 37:187-198.

Blohm, R. J., R. E. Reynolds, J. P. Bladen, J. D. Nichols, J. Hines, K. Pollock, and R. T. Eberhardt. 1987. Mallard mortality rates on key breeding and wintering areas. Transactions of the North American Wildlife and Natural Resources Conference 52:246-257.

Boyce, M. S., A. R. E. Sinclair, and G. C. White. 1999. Seasonal compensation of predation and harvesting. Oikos 87:419-426.

Boyd, H., and G. H. Finney. 1978. Migratory game hunters and hunting in Canada. Canadian Wildlife Service, Report 43.

Burnham, K. P., and D. R. Anderson. 1984. Tests of compensatory vs. additive hypotheses of mortality in Mallards. Ecology 65:105-112.

Burnham, K. P., D. R. Anderson, G. C. White, C. Brownie, and K. H. Pollock. 1987. Design and analysis methods for fish survival experiments based on release-recapture. American Fisheries Society Monograph 5.

Burnham, K. P., G. C. White, and D. R. Anderson. 1995. Model selection strategy in the analysis of capture-recapture data. Biometrics 51:888-898.

Carothers, A. D. 1973. The effects of unequal catchabillity on Jolly-Seber estimates. Biometrics 29:79-100.

Cézilly, F., A. Viallefont, V. Boy, and A. R. Johnson. 1996. Annual variation in survival and breeding probability in Greater Flamingos. Ecology 77:1143-1150.

Cooch, E. G., and F. Cooke. 1991. Demographic changes in a Snow Goose population: biological and management implications. Pages 168-189 in C. M. Perrins, J.-D. Lebreton, and G. J. M. Hirons, editors. Bird population studies. Oxford University Press, Oxford, UK.

Cooke, F., C. M. Francis, E. G. Cooch, and R. T. Alisauskas. 2000. Impact of hunting on population growth of midcontinent Lesser Snow Geese. Pages 17-30 in H. Boyd, editor. Population modelling and management of Snow Geese. Canadian Wildlife Service, Occasional Paper Series 102.

Cooke, F., R. F. Rockwell, and D. B. Lank. 1995. The snow geese of La Pérouse Bay: natural selection in the wild. Oxford University Press, Oxford, UK.

Cormack, R. M. 1964. Estimates of survival from the sighting of marked animals. Biometrika. 51:429-438.

Croxall, J. P., P. Rothery, S. P. C. Pickering, and P. A. Prince. 1990. Reproductive performance, recruitment and survival of wandering albatrosses, Diomedea exulans at Bird Island, South Georgia. Journal of Animal Ecology 59:775-796.

Ebbinge, B. S. 1991. The impact of hunting on mortality rates and spatial distribution of geese wintering in the western palearctic. Ardea 79:197-210.

Ebbinge, B. S., J. B. van Biezen, and H. van der Voet. 1991. Estimation of annual adult survival rates of barnacle geese Branta leucopsis. Ardea 79:73-112.

Errington, P. L. 1945. Some contributions of a fifteen-year study of the northern bobwhite to a knowledge of population phenomena. Ecological Monographs 15:1-34.

Francis, C. M., and F. Cooke. 1992. Sexual differences in survival and recovery rates of lesser snow geese. Journal of Wildlife Management 56:287-296.

Francis, C. M., M. H. Richards, F. Cooke, and R. F. Rockwell. 1992a. Changes in survival rates of Lesser Snow Geese with age and breeding status. Auk 109:731-747.

Francis, C. M., M. H. Richards, F. Cooke, and R. F. Rockwell. $1992 b$. Long-term changes in survival rates of Lesser Snow Geese. Ecology 73:1346-1362.

Francis, C. M., J. R. Sauer, and J. R. Serie. 1998. Effect of 
restrictive harvest regulations on survival and recovery rates of American black ducks. Journal of Wildlife Management 62:1544-1557.

Gauthier, G., and S. Menu. 1997. The use of capture-recapture models in greater snow geese: is there a transient effect of capture and marking on survival? Pages 151-158 in Proceedings of the Survey Methods Section, 24th Annual Meeting of the Statistical Society of Canada, Fredericton, New Brunswick, Canada.

Gauthier, G., L. Rochefort, and A. Reed. 1996. The exploitation of wetland ecosystems by herbivores on Bylot Island. Geoscience Canada 23:253-259.

Greenberg, R. 1980. Demographic aspects of long-distance migration. Pages 493-504 in A. Keast and E. S. Morton, editors. Migrant birds in the neotropics: ecology, behavior, distribution, and conservation. Smithsonian Institution Press, Washington, D.C., USA.

Hargrove, J. W., and C. H. Borland. 1994. Pooled population parameter estimates from mark-recapture data. Biometrics 50:1129-1141.

Hestbeck, J. B. 1994. Survival of Canada geese banded in winter in the Atlantic flyway. Journal of Wildlife Management 58:748-756.

Hestbeck, J. B., J. D. Nichols, and J. E. Hines. 1992. The relationship between annual survival rate and migration distance in mallards: an examination of the time-allocation hypothesis for the evolution of migration. Canadian Journal of Zoology 70:2021-2027.

Hestbeck, J. B., D. H. Rusch, and R. A. Malecki. 1990. Estimating population parameters for geese from band-recovery and mark-recapture data. Transactions of the North American Wildlife and Natural Resources Conference 55: 350-373

Hines, J. E., M. O. Wiebe, S. J. Barry, V. V. Baranyuk, J. P. Taylor, R. McKelvey, S. R. Johnson, and R. H. Kerbes. 1999. Survival rates of lesser snow geese in the Pacific and Western Central Flyways, 1953-1989. Pages 89-109 in R. H. Kerbes, K. M. Meeres, and J. Hines, editors. Distribution, survival, and numbers of lesser snow geese of the Western Canadian Arctic and Wrangel Island, Russia. Canadian Wildlife Service, Occasional Paper 98.

Johnson, S. R., J. O. Schieck, and G. F. Searing. 1995. Neck band loss rates for lesser snow geese. Journal of Wildlife Management 59:747-752

Jolly, G. M. 1965. Explicit estimates from capture-recapture data with both death and immigration-stochastic model. Biometrika 52:225-247.

Lebreton, J.-D. 1995. The future of population dynamic studies using marked individuals: a statistician's perspective. Journal of Applied Statistics 22:1009-1030.

Lebreton, J.-D., K. P. Burnham, J. Clobert, and D. R. Anderson. 1992. Modeling survival and testing biological hypotheses using marked animals: a unified approach with case studies. Ecological Monographs 62:67-118.

Lebreton, J.-D., and J. Clobert. 1991. Bird population dynamics, management, and conservation: the role of mathematical modelling. Pages 105-125 in C. M. Perrins, J.-D. Lebreton, and G. J. M. Hirons, editors. Bird population studies. Oxford University Press, Oxford, UK.

Link, W. A. 1999. Modeling pattern in collections of parameters. Journal of Wildlife Management 63:1017-1027.

Maisonneuve, C., and J. Bédard. 1992. Chronology of autumn migration by greater snow geese. Journal of Wildlife Management 56:55-62.

Maisonneuve, C., and J. Bédard. 1993. Distribution and movements of greater snow geese, Chen caerulescens atlantica, during fall staging in the St. Lawrence estuary, Québec. Canadian Field-Naturalist 107:305-313.

Menu, S., J. B. Hestbeck, G. Gauthier, and A. Reed. 2000.
Effects of neck bands on survival of greater snow geese. Journal of Wildlife Management 64:544-552.

Nichols, J. D. 1991. Responses of North American duck populations to exploitation. Pages $498-525$ in C. M. Perrins, J.-D. Lebreton, and G. J. M. Hirons, editors. Bird population studies. Oxford University Press, Oxford, UK.

Nichols, J. D. 1996. Sources of variation in migratory movements of animal populations: statistical inference and a selective review of empirical results in birds. Pages 147197 in O. E. Rhodes, Jr., R. K. Chesser, and M. H. Smith, editors. Population dynamics in ecological space and time. University of Chicago Press, Chicago, Illinois, USA.

Nichols, J. D., M. J. Conroy, D. R. Anderson, and K. P. Burnham. 1984. Compensatory mortality in waterfowl populations: a review of the evidence and implications for research and management. Transactions of the North American Wildlife and Natural Resources Conference 49:535554.

Nichols, J. D., and F. A. Johnson. 1990. Wood duck population dynamics: a review. Pages 83-105 in L. H. Fredrickson, G. V. Burger, S. P. Havera, D. A. Graber, R. E. Kirby, and T. S. Taylor, editors. Proceedings of the North American Wood Duck Symposium, St. Louis, Missouri, USA.

O'Connor, R. J. 1985. Behavioural regulation of bird populations: a review of habitat use in relation to migration and residency. Pages 105-142 in R. M. Sibly and R. H. Smith, editors. Behavioural ecology: ecological consequences of adaptive behaviour. Blackwell Scientific Publications, Oxford, UK.

Otis, D. L., K. P. Burnham, G. C. White, and D. R. Anderson. 1978. Statistical inference from capture data on closed populations. Wildlife Monographs 62.

Owen, M. 1982. Population dynamics of Svalbard barnacle geese 1979-1980. Aquila 89:229-247.

Owen, M., and J. M. Black. 1989. Factors affecting the survival of barnacle geese on migration from the breeding grounds. Journal of Animal Ecology 58:603-617.

Owen, M., and J. M. Black. 1991. The importance of migration mortality in non-passerine birds. Pages 360-372 in C. M. Perrins, J.-D. Lebreton, and G. J. M. Hirons, editors. Bird population studies. Oxford University Press, Oxford, UK.

Pienkowski, M. W., and P. R. Evans. 1985. The role of migration in the population dynamics of birds. Pages 331352 in R. M. Sibly and R. H. Smith, editors. Behavioural ecology: ecological consequences of adaptive behaviour. Blackwell Scientific Publications, Oxford, UK.

Pradel, R. 1993. Flexibility in survival analysis from recapture data: handling trap-dependence. Pages 29-37 in J.-D. Lebreton and P. M. North, editors. Marked individuals in the study of bird population. Birkhäuser Verlag, Basel, Switzerland.

Pradel, R., E. Cooch, and F. Cooke. 1995. Transient animals in a resident population of snow geese: local emigration or heterogeneity? Journal of Applied Statistics 22:695-710.

Pradel, R., J. E. Hines, J.-D. Lebreton, and J. D. Nichols. 1997. Capture-recapture survival models taking account of transients. Biometrics 53:60-72.

Prevett, J. P., and C. D. MacInnes. 1980. Family and other social groups in snow geese. Wildlife Monographs 71.

Prévot-Julliard, A. C., J.-D. Lebreton, and R. Pradel. 1998. Re-evaluation of adult survival of Black-headed Gulls ( $\mathrm{La}$ rus ridibundus) in presence of recapture heterogeneity. Auk 115:85-95.

Raveling, D. G. 1979. Traditional use of migration and winter roost sites by Canada geese. Journal of Wildlife Management 43:229-235.

Reed, A., J.-F. Giroux, and G. Gauthier. 1998. Population size, productivity, harvest and distribution. Pages 5-31 in 
B. D. J. Batt, editor. The Greater Snow Goose: report of the Arctic Goose Habitat Working Group. Arctic Goose Joint Venture Special Publication, U.S. Fish and Wildlife Service, Washington, D.C., USA, and Canadian Wildlife Service, Ottawa, Ontario, Canada.

Reed, A., R. Stehn, and D. Ward. 1989. Autumn use of Izembek Lagoon, Alaska, by brant from different breeding areas. Journal of Wildlife Management 53:720-725.

Reed, E. T., E. G. Cooch, R. I. Goudie, and F. Cooke. 1998. Site fidelity of Black Brant wintering and spring staging in the strait of Georgia, British Columbia. Condor 100: 426-437.

Rexstad, E. A. 1992. Effects of hunting on annual survival of Canada geese in Utah. Journal of Wildlife Management 56:297-305.

Sandland, R. L., and G. P. Kirkwood. 1981. Estimation of survival in marked populations with possibly dependent sighting probabilities. Biometrika 68:531-541.

Sargeant, A. B., A. H. Allen, and R. T. Eberhardt. 1984. Red fox predation on breeding ducks in mid-continent North America. Wildlife Monographs 89.

Schmutz, J. A., S. E. Cantor, and M. R. Peterson. 1994. Seasonal and annual survival of emperor geese. Journal of Wildlife Management 58:525-535.

Schmutz, J. A., and C. R. Ely. 1999. Survival of greater white-fronted geese: Effects of year, season, sex, and body condition. Journal of Wildlife Management 63:1239-1249. Schmutz, J. A., and J. A. Morse. 2000. Effects of neck collars and radiotransmitters on survival and reproduction of emperor geese. Journal of Wildlife Management 64:231-237.

Seber, G. A. F. 1965. A note on the multiple-recapture census. Biometrika 52:249-259.

Smith, G. W., and R. E. Reynolds. 1992. Hunting and mallard survival, 1979-88. Journal of Wildlife Management 56: 306-316.

Teunissen, W., B. Spaans, and R. H. Drent. 1985. Breeding success in brent in relation to individual feeding opportunities during spring staging in the Wadden Sea. Ardea 73:109-119.

van der Jeugd, H., and K. Larsson. 1998. Pre-breeding survival of barnacle geese Branta leucopsis in relation to fledgling characteristics. Journal of Animal Ecology 67:953966.

Ward, D. H., E. A. Rexstad, J. S. Sedinger, M. S. Lindberg, and N. K. Dawe. 1997. Seasonal and annual survival of adult Pacific brant. Journal of Wildlife Management 61: 773-781.

White, G. C. 1983. Numerical estimation of survival rates from band-recovery and biotelemetry date. Journal of Wildlife Management 47:716-728.

\section{APPENDIX A}

A table presenting results of test 2.Ct of RELEASE, which assesses short-term dependence in sighting probabilities, is available in ESA's Electronic Data Archive: Ecological Archives E082-034-A1.

\section{APPENDIX B}

A table presenting results of test 2.Cm* of RELEASE, which assesses long-term dependence in sighting probabilities, is available in ESA's Electronic Data Archive: Ecological Archives E082-034-A2. 